\title{
Evaluation of L-fucose and Sialic Acid Levels in Patients With Colorectal Cancer and Control Subject
}

\author{
Roya Abbasi Natajomrani ${ }^{1}$ (D), Durdi Qujeq ${ }^{2^{*}}$ (D), Vahid Hosseini ${ }^{3}$ (D), Reza Hajihosseini ${ }^{{ }^{*}}$ (D)
}

1. Department of Biology, Payame Noor University, Tehran, Iran.

2. Department of Biochemistry, Faculty of Medicine, Babol University of Medical Sciences, Babol, Iran

3. Gut and Liver Research Center, Mazandaran University of Medical Sciences, Sari, Iran

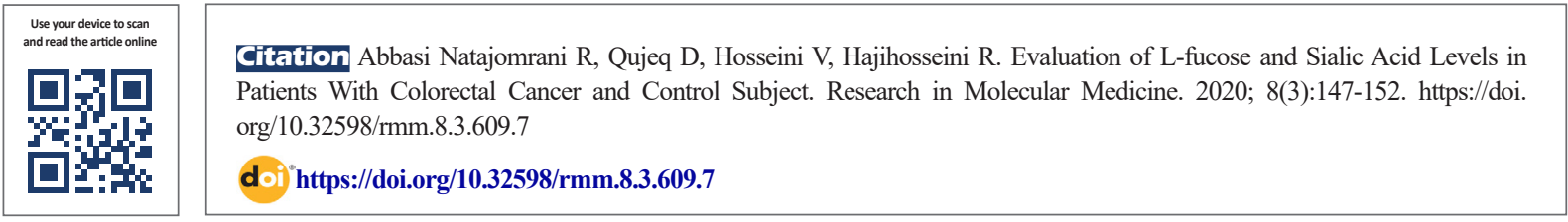

\section{(1) (1)}

Article Type:

Research Article

Article info:

Received: 23 May 2020

Revised: 29 Jun 2020

Accepted: 22 Jul 2020

Keywords:

CRC (colorectal cancer), AUC (area under curve), ROC (receiver operating characteristic)

\begin{abstract}
A B S T RA C T
Background: Currently, glycans, which are known as functional molecules in the biological system, are being under study as potential cancer markers. This study aimed to determine the level of serum L-fucose and sialic acid as the biomarkers in patients with colorectal cancer (CRC).

Materials and Methods: The patients with CRC ( $\mathrm{n}=40,20$ men and 20 women) participated in the present study. The spectrophotometric method was used to measure the levels of L-fucose and sialic acid in the serum of the patients. SPSS v. 21 was used to analyze the obtained data. The results were expressed as Mean \pm SD.

Results: The Mean \pm SD L-fucose level in patients with CRC was $27.46 \pm 4.8 \mathrm{ng} / \mathrm{mL}$, which was more than this level in the healthy control group $(18.64 \pm 3.1 \mathrm{ng} / \mathrm{mL})$. Also, the Mean \pm SD serum concentration of sialic acid in patients with CRC was $2.1 \pm 0.41 \mathrm{ng} / \mathrm{mL}$, which was more than the Mean \pm SD sialic acid level of $1.23 \pm 0.21 \mathrm{ng} / \mathrm{mL}$ in the healthy controls.

Conclusion: Serum concentration of $\mathrm{L}-$ fucose and sialic acid increased significantly $(\mathrm{P}<0.05)$ in patients with CRC compared with the healthy controls. We believe that determining serum L-fucose and sialic acid levels could be useful for the detection of CRC patients in the early stage.
\end{abstract}

\section{Introduction}

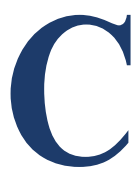

olorectal Cancer (CRC) is a common malignancy with poor prognosis and survival rates, and one of the leading causes of cancer-related deaths worldwide. $\mathrm{CRC}$ is a disease originating from the epithelial cells lining the colon or rectum of the gastrointestinal tract. Symptoms of CRC are blood in the stool, change in bowel movements, weight loss, and feeling tired. It causes might be old age, lifestyle, and genetic disorders. CRC diagnosis is performed by the sampling of areas of the colon suspicious for possible tumor development.

CRC can be observed in the uncontrolled growth of epithelial cells in the colon and rectum layers in the gastrointestinal system without clinical symptoms [1]. Therefore, studies based on the molecular differences

* Corresponding Author:

Reza Hajhosseini, PhD.

Address: Department of Biology, Payame Noor University, Tehran, Iran

Phone: +98 (911) 1261709

E-mail:hosseini@pnu.ac.ir 
between patients with CRC and healthy sera can be helpful for the early diagnosis of CRC [2].

One of the biomarkers in this issue could be glycans. They are known as functional molecules in the biological system, exist in the form of glycoproteins, glycolipids, or other glycoconjugates [3]. Glycosylation is one of the most common and complex structural post-translational modifications to the proteins [4]. The natural process of glycosylation is disrupted through cellular malignancy. These changes alter tumor cell surface glycan that binds to proteins and lipids at the level of the cancer cells and plays a key role in the phenotype and interactions of these cells with the surrounding environment [5].

Monosaccharides such as L-fucose and sialic acid with different glycosylated bonds between different parts of the antigens at the cellular surface. Excessive expression of fucosylated antigens has been reported in many cancers, in particular, the high expression of fucosylated antigens related to fucosyltransferase has been shown in colon cancer [6]. The amount of L-fucose is increased in colorectal cancer tissues. L-fucose plays a critical role in changing human molecules in immunological response and signal transmission pathways $[7,8]$.

Sialic acid-based glycoconjugates cover the surface of many different cell types [9]. Sialoglycans are expressed in many types of cells. They regulate the structure, stability, mobility, and function of glycoproteins and glycolipids [10]. Therefore, along with clinical diagnostic methods, serum levels of L-fucose and sialic acid can be measured as an effective marker for cancer detection. In this study, serum concentrations of L-fucose and sialic acid were used to determine the difference between these factors in the group of patients with CRC and healthy subjects to find the role of L-fucose and sialic acid as diagnostic markers for CRC.

\section{Materials and Methods}

\section{Patients and samples}

Blood samples were collected from subjects participating in CRC screening ( $\mathrm{n}=40,20$ men and 20 women) in Mazandaran Educational Hospital and Toba Clinic, Mazandaran University of Medical Sciences, Sari, Iran, from November 2017 and January 2019. Clinical and pathological information was collected during the consultation. The healthy control group included 40 healthy volunteers ( 8 males and 32 females), aged 30-70 years. To reduce and control other interveners, the selection of controlled and studied groups were matched by age, region, weight, and nutrition conditions. Also, it was one-to-one matching. Pathological and clinical staging systems were used for the staging of colorectal cancer. Patients are in stage 1 when cancer has grown through the muscularis mucosa into the submucosa, and then into the muscularis propria. Also, in grade 1 patients (low grade) the cancerous tissue looks most like normal cells. We had available information on medication use (e.g. NSAIDs) and medical history. The inclusion and exclusion criteria apply to both patients and healthy controls.

The inclusion criteria include CRC patients aged from 30 to 70 years old, who had been diagnosed by consulting with a gastroenterologist.

Exclusion criteria include patients over 70 years and under 30 years; those undergoing chemotherapy, or radiotherapy; having other cancers, and malignant and autoimmune disease.

A blood sample of 5-mL was taken from each case in a sterile tube non-metallic vein. Then, the blood was kept to be clotted. Afterward, centrifugation was performed at $3000 \mathrm{rpm}$ for $10 \mathrm{~min}$ to extract the serum.

In this study, the spectrophotometric method was used to measure the levels of L-fucose and sialic acid in sera. Measuring L-fucose, is based on oxidation of L-fucose to L-fucono-lactone by L-fucose dehydrogenase which leads to the reduction of NAD+ to NADH. Therefore, the free L-fucose test was based on the amount of NADH with the change in absorbance of $340 \mathrm{~nm}$.

Sialic acid measurements were performed based on the thiobarbituric acid method. The absorbance of the upper red solution of the cyclohexanone phase is determined at $549 \mathrm{~nm}$ in a spectrophotometer (UNICO-AJU1104001).

This study was approved by the Human Subject's Ethics Board of Payame Noor University and was conducted following the Helsinki Declaration of 1975 (revised in 2013). All protocols involving patients and control subjects were confirmed by the Ethics Committee of Payame Noor University (Code: IR.PNU.REC.1397.036).

\section{Statistical analysis}

SPSS V. 21 was used to analyze the data. The results were expressed as Mean \pm SD. The t-test or Mann-Whitney test were used to compare the colon cancer patients and control groups in terms of the serum L-fucose and sialic acid levels. Receiver Operating Characteristic (ROC) curve analysis was performed to determine the 
significance of the relationship between L-fucose and sialic acid to evaluate the diagnostic function for CRC. The values of $\mathrm{P}<0.05$ were statically significant for the difference between groups.

\section{Results}

Table 1 presents the demographic characteristics in patient and healthy control groups. Patients ( $n=40,20$ women and 20 men) and healthy subjects ( $n=40,32$ women and 8 men) who had inclusion criteria participated in this study and the Mean \pm SD age of patients was $60 \pm 9.42$ years (ranged 30-70 years), and the Mean $\pm \mathrm{SD}$ age of control group was $43 \pm 13.4$ years (ranged $30-70$ years).

Table 2 presents the distribution of serum L-fucose and sialic acid levels in patient and healthy control groups. The Mean \pm SD L-fucose level was $27.46 \pm 4.8(\mathrm{ng} / \mathrm{mL})$ in patients with $\mathrm{CRC}$, which was more than the Mean $\pm \mathrm{SD}$ level of L-fucose in the healthy control group (18.64 \pm 3.1 $\mathrm{ng} / \mathrm{mL}$ ). The serum Mean $\pm \mathrm{SD}$ concentration of sialic acid in patients with CRC was $2.1 \pm 0.41 \mathrm{ng} / \mathrm{mL}$, which was more than the Mean \pm SD sialic acid level of the healthy controls $(1.23 \pm 0.21 \mathrm{ng} / \mathrm{mL})$. Figure 1 demonstrates the levels of L-fucose and sialic acid in patients with CRC and normal human serum determined by the spectrophotometric. The serum concentration of $\mathrm{L}$-fucose and sialic acid increased significantly $(\mathrm{P}<0.05)$ in patients with
CRC in comparison to the controls in our study (Figure 1). The area under the curve (AUC) was used to express the results of the ROC curve analysis. AUC of L-fucose and sialic acid were 0.93 and 0.98 , respectively (Figure 2). Our results demonstrated that colorectal cancer has grown through the mucosa and invaded the muscular layer of the colorectal. It has not spread into nearby tissues or lymph nodes.

\section{Discussion}

The main findings of this study are that the amount of L-fucose and sialic acid in the serum of patients with CRC increased when compared with those in the healthy controls. Interestingly, higher levels of these factors in the serum was associated with changes in the patients' signs and symptoms such as worsening constipation, blood in the stool, decrease in stool caliber (thickness), loss of appetite, loss of weight, and nausea or vomiting, change in bowel movements, weight loss, feeling tired,. In this regard, unusual glycosylation is considered as a sign of malignant cellular development [4, 11, 12]. L-fucose changes human molecules through the immunological response and signal transmission pathways. Researchers reported that serum levels of L-fucose in patients with malignant tumors increases [13-15].

Table 1. Demographic characteristics of patients with colorectal cancer and healthy controls $(n=40)$

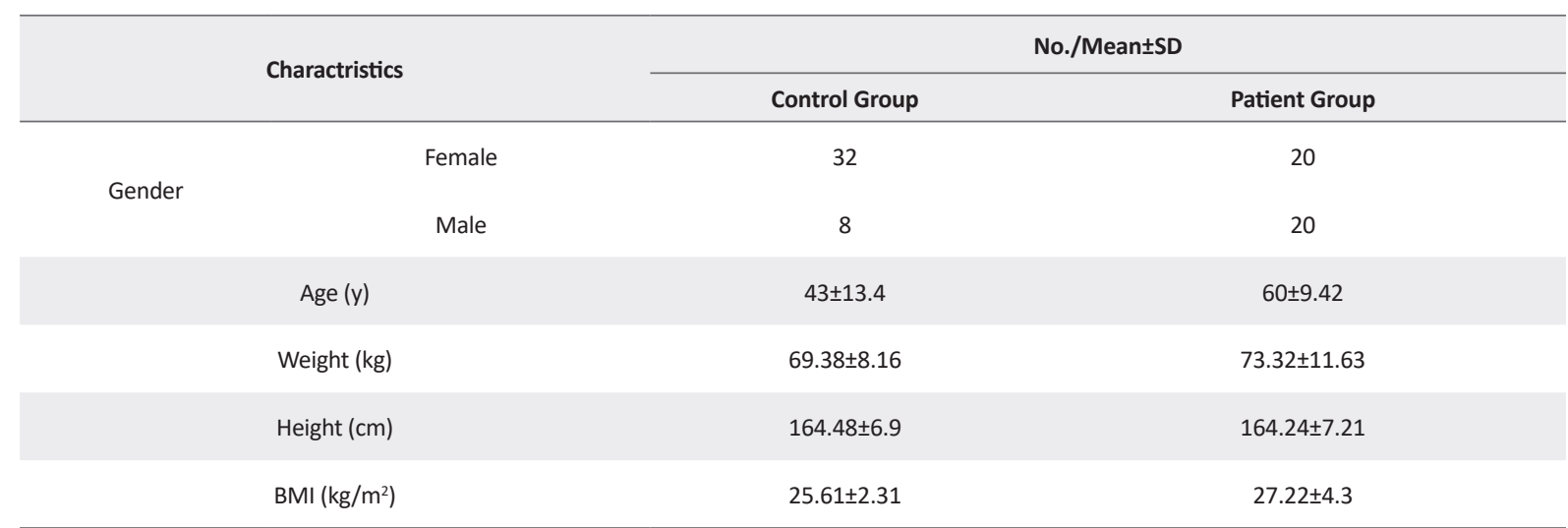

Table 2. Serum L-fucose and sialic acid levels in patients with colorectal cancer and healthy controls

\begin{tabular}{|c|c|c|c|}
\hline \multirow{2}{*}{ Variables } & \multicolumn{2}{|c|}{ Mean \pm SD } & \multirow{2}{*}{$\mathrm{P}^{*}$} \\
\hline & Patients with Colorectal Cancer & Healthy Control & \\
\hline L-fucose level (ng/mL) & $27.46 \pm 4.8$ & $18.64 \pm 3.1$ & 0.001 \\
\hline Sialic acid level ( $\mu \mathrm{g} / \mathrm{dL})$ & $2.1 \pm 0.41$ & $1.23 \pm 0.21$ & 0.001 \\
\hline
\end{tabular}



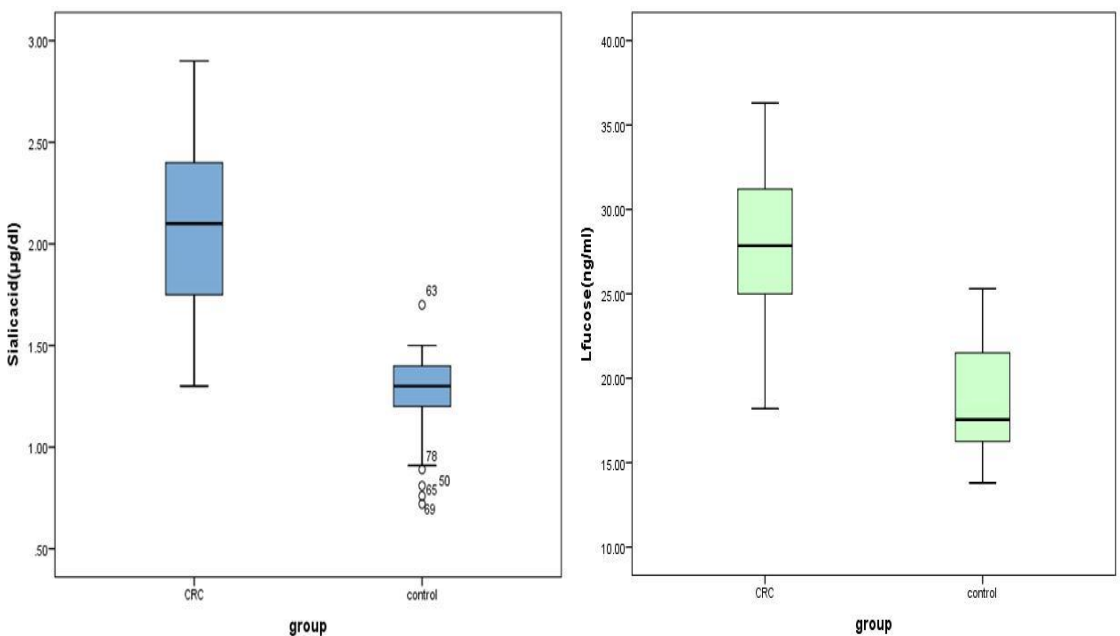

grmm

Figure. 1 Level of L-fucose and sialic acid in patients with colorectal cancer and normal human serum by spectrophotometric method

A: L-fucose $(\mathrm{P}<0.05)$; B: Sialic acid $(\mathrm{P}<0.05)$; The $\mathrm{t}$-test was used to compare with the respective normal group

Researchers measured the urine and sera L-fucose in healthy subjects and patients with cancer. In this study, out of 50 patients with colorectal cancer, 32 cases had significantly higher values of urinary free L-fucose compared with the healthy subjects, but free-fucose concentrations in serum were similar between the two groups. This finding, with respect to the relationship between L-fucose with CRC, is contrary to our results, which probably is due to differences in test conditions, such as enzyme concentration and sera sample volume [7]. Other researchers studied serum L-fucose relationships with various malignant diseases and reported that serum L-fucose in malignant diseases was different from that in healthy controls $[13,15]$.

Feijoo-Carnero et al. determined the amount of total sialic acid levels in 123 patients with primary colorectal adenocarcinoma and compared the results with 72 healthy subjects. They suggest that the serum total sialic acid could be useful for the detection of CRC patients in the early stage. The findings of this research are consistent with our findings [14]. Researchers analyzed the

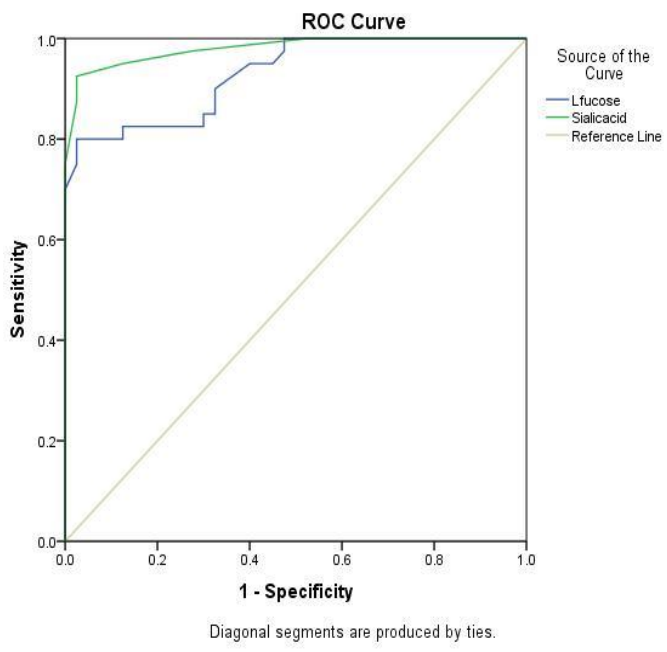

grmm

Figure 2. Analysis of L-fucose and sialic acid of sensitivity and specificity in the diagnosis of colorectal cancer by Receiver Operating Characteristic (ROC) curve

Data were collected from the spectrophotometric method for L-fucose and sialic acid (considering the larger test result indicates more positive test). ROC curve analysis shows the area under ROC as 0.93 and 0.98 . 
sialic acid and L-fucose composition in human colorectal adenocarcinoma and reported a significant increase in these residues in the epithelial cells but no significant differences between normal and malignant colorectal tissues in the L-fucose residues [16]. Our findings confirm these results.

To investigate the biomarkers in a variety of cancers, several markers have been recognized to identify cancers $[17,18]$. In this regard, it can be noted that in recent years, researchers have concentrated on the DNA damage response in cancer and some of the effective factors in the pathogenesis of the human disease $[19,20]$. There is increasing evidence to support the measurement of specific biomarkers in biological samples of patients with cancer $[21,22]$. Furthermore, researchers suggest that the regulatory functions of circular RNAs and targeting the mammalian target of rapamycin signaling are effective in cancer therapy $[23,24]$. Also, much evidence supports the CRISPR/Cas9 technology and it can be used to better understand the pathogenesis of diseases [25]. The relative abundance of seven IgG glycans, fucose, sialic acid, galactose, and bisecting change during tumor growth in CRC [26]. The caudal-related homeobox protein 1 in altering the N-glycosylation of colorectal cancer cells is important [27]. Further studies are required to achieve a greater understanding of these biomarkers in human cancer. We believe that this endower will contribute to the development of future research in the area of the mechanism of biomarkers to improve the quality of life of patients with cancer.

Limitations In addition to all these positive findings and recommendations, some of the limitations of our study should be noted. First of all, the small sample size might result in the loss of the power analysis of L-fucose and sialic acid levels in patient sera. Secondly, we did not have data on the stage of CRC.

\section{Conclusion}

The results show the sensitivity and specificity of L-fucose and sialic acid as a potential biomarker in the diagnosis of the patients with CRC. Serum levels of L-fucose and sialic acid could be used as an easy, non-invasive, costeffective, biochemical indicator of CRC detection and as a prognostic evaluation tool. Further studies on a large scale might prove serum L-fucose and sialic acid as an effective biomarker in the diagnosis and management of CRC.

\section{Ethical Considerations}

\section{Compliance with ethical guidelines}

All protocols involving patients and control subjects were approved by the Ethics Committee of Payame Noor University (Code: IR.PNU.REC.1397.036).

\section{Funding}

The present paper was extracted from $\mathrm{PhD}$. thesis of Roya Abbasi Natajomrani at the Department of Biochemistry, Faculty of Sciences, Payame Noor University, Tehran (No.: 2-1396/10/26).

\section{Authors contribution's}

Conceptualization, supervision: Reza Hajihossini , Durdi Qujeq; Methodology: Roya Abbasi Natajomrani, Vahid Hosseini; Investigation, writing - review \& editing: All authors; Writing - original draft: Roya Abbasi Natajomrani; Funding acquisition: Resources: Reza Hajihossini; Analysis the data: Reza Hajihosseini.

\section{Conflict of interest}

The authors declared no conflict of interest.

\section{Acknowledgements}

The authors appreciatively acknowledge the personnel of the Mazandaran Educational Hospital and Toba Clinic.

\section{References}

[1] Fleming M, Ravula S, Tatishchev SF, Wang HL. Colorectal carcinoma: Pathologic aspects. J Gastrointest Oncol. 2012 3(3):153-73. [Doi:10.3978/j.issn.2078-6891.2012.030][PMID] [PMCID].

[2] No authors. Colorectal cancer. Nature Reviews. Dis Primers. 2015; 1:15066. [DOI:10.1038/nrdp.2015.66] [PMID]

[3] Li M, Song L, Qin X. Glycan changes: Cancer metastasis and anti-cancer vaccines. J Biosci. 2010; 35(4):665-73. [DOI:10.1007/ s12038-010-0073-8] [PMID]

[4] Ferreira JA, Magalhães A, Gomes J, Peixoto A, Gaiteiro C, Fernandes E, et al. Protein glycosylation in gastric and colorectal cancers: Toward cancer detection and targeted therapeutics. Cancer Lett. 2017; 387:32-45. [DOI:10.1016/j.canlet.2016.01.044] [PMID] 
[5] Shriver Z, Raguram S, Sasisekharan R. Glycomics: A pathway to a class of new and improved therapeutics. Nature Reviews Drug Discovery. 2004; 3(10):863-73. [DOI:10.1038/nrd1521] [PMID]

[6] Blanas A, Sahasrabudhe NM, Rodríguez E, van Kooyk Y, van Vliet SJ. Fucosylated antigens in cancer: An alliance toward tumor progression, metastasis, and resistance to chemotherapy. Front Oncol. 2018; 8:39. [DOI:10.3389/fonc.2018.00039] [PMID] [PMCID]

[7] Sawke NG, Sawke GK. Serum fucose level in malignant diseases.Indian J Cancer. 2010; 47(4):452-7. [DOI:10.4103/0019509X.73549] [PMID]

[8] Zhao Q, Zhan T, Deng Z, Li Q, Liu Y, Yang S, et al. Glycan analysis of colorectal cancer samples reveals stagedependent changes in CEA glycosylation patterns. Clin Proteomics. 2018; 15:9. [DOI:10.1186/s12014-018-9182-4] [PMID] [PMCID]

[9] Glavey SV, Huynh D, Reagan MR, Manier S, Moschetta M, Kawano Y, Roccaro AM, et al. The cancer glycome: Carbohydrates as mediators of metastasis. Blood Rev. 2015; 29(4):269-79. [DOI:10.1016/j.blre.2015.01.003] [PMID]

[10] Haq S, Sambi M, Qorri B, Mendonza N, SzewczukMR. Aberrant sialic acid expression and its role in regulating metastasis in colorectal cancer. Adv Res Gastroenterol Hepatol. 2017; 7(2):22-26. [DOI:10.19080/ARGH.2017.07.555707]

[11] Das V, Kalita J, Pal M. Predictive and prognostic biomarkers in colorectal cancer: A systematic review of recent advances and challenges. Biomed Pharmacother. 2017; 87:8-19. [DOI:10.1016/j.biopha.2016.12.064] [PMID]

[12] Varki A, Cummings RD, Esko JD, Stanley P, Hart GW, Aebi $\mathrm{M}$, et al . Essentials of glycobiology. $3^{\text {rd }}$ editio. New York: Cold Spring Harbor Laboratory Press; 2009.

[13] Redwin Dhas Manchil P, Joy ET, Shashi Kiran M, Eugenia Sherubin J, Farakath Khan M, Aravind BS. Correlation of serum levo-fucose levels as a biomarker with tumor node metastasis staging in oral cancer patients. J Pharm Bioallied Sci. 2016; 8(Suppl 1):S147-S150. [PMID] [PMCID]

[14] Feijoo-Carnero C, Rodríguez-Berrocal FJ, Páez de la Cadena M, Ayude D, de Carlos A, Martínez-Zorzano VS. Clinical significance of preoperative serum sialic acid levels in colorectal cancer: Utility in the detection of patients at high risk of tumor recurrence. Int J Biol Markers. 2004; 19:38-45. [DOI:10.5301/ JBM.2008.576] [PMID]

[15] Schneider M, Al-Shareffi E, Haltiwanger RS. Biological functions of fucose in mammals. Glycobiology. 2017; 27:601-18. [DOI:10.1093/glycob/cwx034] [PMID] [PMCID]

[16] Fernández-Rodríguez J, Feijoo-Carnero C, Merino-Trigo A, Páez de la Cadena M, Rodríguez-Berrocal FJ, de Carlos A, et al. Immunohistochemical analysis of sialic acid and fucose composition in human colorectal adenocarcinoma.Tumour Biol. 2000 21(3):153-64. [DOI:10.1159/000030122] [PMID]

[17] Mahmoudi A, Qujeq D, Daneshdoust D, Karimi M. Determination of serum survivin for prognostic role in esophageal cancer. J Res Appl Basic Med Sci. 2020; 6(1):9-13.

[18] Aghcheli K, Parsian H, Qujeq D, TalebiM, Mosapour A, Khalilipour E, et al. Serum hyaluronic acid and laminin as potential tumor markers for upper gastrointestinal cancers. Eur J Intern Med. 2012; 23(1):58-64. [DOI:10.1016/j.ejim.2011.07.018] [PMID]
[19] Samavarchi Tehrani S, MahmoodzadehHosseini H, Yousefi T, Abolghasemi M, Qujeq D, Maniati M, et al. The crosstalk between trace elements with DNA damage response, repair, and oxidative stress in cancer. J Cell Biochem. 2018; 120(2). [DOI:10.1002/jcb.27617] [PMID]

[20] Nejat Pish-Kenari F, Qujeq D, Maghsoudi H. Some of the effective factors in the pathogenesis of gastro-oesophageal reflux disease. J Cell Mol Med. 2018; 22(12):6401-4. [DOI:10.1111/ jcmm.13939] [PMID] [PMCID]

[21] Abolghasemi M, Yousefi T, Maniati M, Qujeq D. The interplay of Klotho with signaling pathway and microRNAs in cancers. J Cell Biochem. 2019; 120:14306-17. [DOI:10.1002/jcb.29022] [PMID]

[22] Yousefi M, Qujeq D, Shafi H, Hajian-Tilaki K. Serum and urine levels of sarcosine in benign prostatic hyperplasia and newly diagnosed prostate cancer patients. J Kermanshah Univ Med Sc. 2020; 24(1):e97000 [DOI:10.5812/jkums.97000]

[23] Tamddoni A, Mohammadi E, Sedaghat F, Qujeq D. As'Habi A. Anticancer effects of curcumin via targeting the mammalian target of rapamycin complex 1 (mTORC1) signaling pathway. Pharmacol Res. 2020; 156:104798. [DOI:10.1016/j. phrs.2020.104798] [PMID]

[24] Soghli N, Qujeq D, Yousefi T, SoghliN. The regulatory functions of circular RNAs in osteosarcoma. Genomics. 2020 112(4):2845-56. [DOI:10.1016/j.ygeno.2020.03.024] [PMID]

[25] Mohammadzadeh I, Qujeq D, YousefiT Ferns GA, Maniati M, Vaghari-Tabari M. CRISPR/Cas9 gene editing: A new therapeutic approach in the treatment of infection and autoimmunity. IUBMB Life. 2020; 72(8):1603-21. [DOI:10.1002/iub.2296] [PMID]

[26] Gu Y, Han J, Liu X, Pan Y, Xu X, Sha J, Ren S, Gu J. Dynamic alterations in serum IgG N-glycan profiles in the development of colitis-associated colon cancer in mouse model. Biochim Biophys Acta Gen Subj. 2020; 1864(10):129668. [DOI:10.1016/j. bbagen.2020.129668] [PMID]

[27] Holst S, Wilding JL, Koprowska K, Rombouts Y, Wuhrer M. N-Glycomic and transcriptomic changes associated with CDX1 mRNA expression in colorectal cancer cell lines. Cells. 2019; 8(3):273. [DOI:10.3390/cells8030273] [PMID] [PMCID] 